\title{
Is There Evidence to Support a Relationship between Temporomandibular Disorders (TMD) and Headache? - A Systematic Review.
}

\author{
Justyna Agnieszka Lemejda ${ }^{1}$, Jolanta E. Loster ${ }^{2}$ \\ 1,2 Department of Dental Prosthetics, Institute of Dentistry, Jagiellonian University Medical College, \\ Jagiellonian University, ul. Montelupich, Krakow, Poland.
}

\section{ABSTRACT}

\section{BACKGROUND}

Headache and migraine can lead to depression by worsening the mood and producing an unpredictable disorganisation of life. Temporomandibular disorders (TMD) are associated with headache. Tenderness of the masticatory muscles, especially in young patients, and pain in the temporomandibular joint area are also associated with migraine, which can cause headaches of varying degrees of intensity. This article presents a literature review on the relationship between the occurrence of headache and the symptoms of TMD.

\section{METHODS}

The inclusion criteria were English-language articles published since 2007 that classify TMD using the Research Diagnostic Criteria for Temporomandibular Disorders (RDC / TMD) questionnaire, and which described headache using the International Classification for Headache Disorders (second and third editions) or the headache screening questionnaire (HSQ).

\section{RESULTS}

Fifteen qualifying articles were found. Ten of these were included in the analysis. The authors noticed that the diagnoses were unclear, though it seems that these disorders have a similar background.

\section{CONCLUSION}

The current literature review confirms the relationship between TMD and headache. The authors of the articles generally agree that problems are more common in women, and that further research should be conducted on the correlation between these disorders. It is necessary to conduct further research using standardised assessment scales of both TMD and headache to compare the results. Such studies will allow a meta-analysis of the data, which will help to broaden our understanding of these problems and find conducive factors.

\section{KEY WORDS}

Temporomandibular Disorders, Headache, Tension-Type Headache, Headache Disorders, Headache Classification
Corresponding Author: Dr. Justyna Lemejda, Department of Dental Prosthetics, Institute of Dentistry, ul. Montelupich 4, 31-155, Kraków, Poland,

E-mail: justyna.lemejda@doctoral.uj.edu.pl

DOI: $10.14260 /$ jemds/2021/380

How to Cite This Article:

Lemejda JA, Loster JE. Is there evidence to support a relationship between temporomandibular disorders (TMD) and headache? - a systematic review. J Evolution Med Dent Sci 2021;10(24):18401844, DOI: $10.14260 /$ jemds/2021/380

Submission 20-10-2020, Peer Review 17-04-2021, Acceptance 23-04-2021, Published 14-06-2021.

Copyright (C) 2021 Justyna Agnieszka Lemejda et al. This is an open access article distributed under Creative Commons Attribution License [Attribution 4.0 International (CC BY 4.0)] 


\section{BACKGROUND}

Headache is the most prevalent disorder and can be connected with other diseases. The prevalence is about $5 \%$ in adolescents. ${ }^{1}$ The frequency, duration, site and location of the headache can be different. It is possible to distinguish premonitory symptoms like mood and irritability. One of the examples of more problematic headache is migraine. Migraine is a chronic neurological disorder that causes severe headaches of varying degrees of intensity; it can be described as a primary disorder of the brain and is a form of neurovascular disorder. There are two types of migraine: classic and common. In the former, a visual aura precedes the headache, while in the latter there is no aura. Common migraine attacks are associated with vomiting and light sensitivity, and if untreated may last 4 to 72 hours. Ion-channel mutations influence the prevalence of migraine without aura. Migraine occurs in $15 \%$ of the population and troubles more women than men. ${ }^{2}$ Researchers have described migraines that occur among patients suffering from depression, and have pointed out that migraines can diminish quality of life. ${ }^{3}$

It is interesting to determine the relationship between the prevalence of headache or migraine headaches and temporomandibular disorders (TMD). The 1978 research of Magnusson and Carlsson ${ }^{4}$ confirmed the relationship between the afflictions. These researchers established two groups of 80 patients, one of which suffered from TMD, and the other did not. All patients completed a questionnaire of the researchers' in the topic of recurring headaches; they were also clinically tested. It was noted that teeth-clenching is associated with the headaches. Patients were also classified using the Eichner classification to define the relationship between the exacerbation of pain and the type of dental occlusal contact. The results showed that exacerbation and incidence of headaches were more intense in the patients with TMD. It was further noted that severe headaches were more often reported by women than men.

Researchers used a classification that was known and used in dentistry at the time. Currently, standardised questionnaires are used, which are translated into many languages. This makes it possible to compare the examination results of independent research centers.

It is worth mentioning Ciancaglini et al. ${ }^{5}$ who also showed a relationship between TMD and headaches among adults. The authors conducted a questionnaire-based study of 483 adults from northern Italy using the Helkimo index. Patients marked spots of pain on previously prepared patterns. The researchers also noted a relationship between headaches and TMD, and more frequent afflictions occurring among women. Despite the availability of RDC / TMD and International Classification for Headache Disorders (ICHD-I), Ciancaglini et al. did not use these questionnaires.

These researchers were soon followed by others. To describe and diagnose migraine headaches, a range of different classifications of headache were used, such as the second edition of the International Classification for Headache Disorders (ICHD-II), created by Jes Olesen and co-researchers, the International Classification of the Headache Disorder, third edition (ICHD-3), the headache screening questionnaire (HSQ), 6,7 the International Headache Society (IHS) questionnaire and the Allodynia Symptom Checklist (ASC-12). Specially prepared questionnaires designed by authors for their own research were also used. To diagnose TMD, researchers used the Research Diagnostic Criteria for temporomandibular disorders RDC / TMD, ${ }^{8}$ Helkimo's dysfunction index, ${ }^{9}$ or the questionnaire of Agerberg and Helkimo. ${ }^{10}$

The use of different classifications of headache and TMD precludes comparison of their findings, as different scales evaluate different parameters. This also makes meta-analyses impossible. However, although various scales have been used to evaluate dysfunction, it is still worth paying attention to the results, which may turn out to be convergent.

In order to draw reliable conclusions, the literature has been assessed by selecting papers in which the authors used the highest-rated RDC / TMD questionnaire for the TMD survey. For headache assessment, the articles were selected in which one of the two most common questionnaires were used: The International Classification for Headache Disorders (second or third edition) or the Headache Screening Questionnaire (HSQ).

We wanted to study the relationship between the occurrence of headache and symptoms of TMD through literature review.

\section{METHODS}

\section{Systematic Review of Literature}

The literature review was performed on 20 February 2019. The PubMed, Embase and Scopus databases were used for the bibliographical search. Present study also performed a manual literature search using the following keywords: temporomandibular disorders, migraine, tension-type headache, temporomandibular dysfunction, headache disorders, migraine classification and headache classification. The inclusion criterion was that the articles be Englishlanguage original research since 2007, using the RDC / TMD questionnaire to assess the degree of TMD, and either ICHD-II, ICHD-3,11 or the IHS for questionnaire for headache diagnosis. The articles selected for analysis were discussed in chronological order using the publication date. The set of selected publication with specified classification are collected in Table 1. The exclusion criteria were review articles and research where patients were under 13 years.

\section{RESULTS}

The search of the PubMed, Embase and Scopus databases yielded fifteen articles, of which ten qualified for further analysis after evaluating their summaries. The list of analyzed articles is presented in Table 1, arranged by publication date. Publications that met the inclusion criterion came from research centers in Europe and the Americas.

\section{DISCUSSION}

The first article, from 2007, by Glaros et al.12, describes research that involved two groups of patients: one with chronic headache and the non-headache control group. 


\begin{tabular}{|c|c|c|c|c|c|c|c|c|}
\hline Sl. No. & Author & Article Title & Year & $\begin{array}{c}\text { Headache } \\
\text { Classification }\end{array}$ & $\begin{array}{c}\text { TMD } \\
\text { Classification }\end{array}$ & Country & $\begin{array}{l}\text { Type of } \\
\text { Study }\end{array}$ & $\begin{array}{c}\text { No. of } \\
\text { Subjects }\end{array}$ \\
\hline 1. & Glaros $^{12}$ & $\begin{array}{c}\text { Headache and } \\
\text { temporomandibular disorders: } \\
\text { evidence for diagnostic and } \\
\text { behavioural overlap }\end{array}$ & 2007 & $\begin{array}{l}\text { ICHD-II } \\
\text { HSQ }\end{array}$ & RDC / TMD & USA & $\begin{array}{l}\text { Case-control } \\
\text { study }\end{array}$ & 44 \\
\hline 2. & Ballegaard ${ }^{13}$ & $\begin{array}{l}\text { Are headache and } \\
\text { temporomandibular disorders } \\
\text { related? A blinded study }\end{array}$ & 2008 & ICHD-II & RDC / TMD & Denmark & $\begin{array}{l}\text { Case-control } \\
\text { study }\end{array}$ & 99 \\
\hline 3. & $\begin{array}{l}\text { Bevilaqua- } \\
\text { Grosii }^{14}\end{array}$ & $\begin{array}{l}\text { Temporomandibular disorders } \\
\text { and cutaneous allodynia are } \\
\text { associated in individuals with } \\
\text { migraine }\end{array}$ & 2009 & $\begin{array}{l}\text { ICHD-II } \\
\text { (ASC-12) }\end{array}$ & $\mathrm{RDC} / \mathrm{TMD}$ & Brazil & $\begin{array}{l}\text { Case-control } \\
\text { study }\end{array}$ & 55 \\
\hline 4. & Troeltzsch $^{15}$ & $\begin{array}{l}\text { Prevalence and association of } \\
\text { headaches, temporomandibular } \\
\text { joint disorders, and occlusal } \\
\text { interferences }\end{array}$ & 2011 & IHS & RDC / TMD & Germany & $\begin{array}{l}\text { Cross- } \\
\text { sectional } \\
\text { study }\end{array}$ & 1031 \\
\hline 5. & Melo $^{16}$ & $\begin{array}{l}\text { Temporomandibular disorders } \\
\text { in headache patients }\end{array}$ & 2012 & ICHD-II & $\mathrm{RDC} / \mathrm{TMD}$ & Brazil & $\begin{array}{l}\text { Case-control } \\
\text { study }\end{array}$ & 60 \\
\hline 6. & Franco $^{17}$ & $\begin{array}{l}\text { Migraine is the most prevalent } \\
\text { primary headache in individuals } \\
\text { with temporomandibular } \\
\text { disorders }\end{array}$ & 2014 & ICHD-II & RDC / TMD & Brazil & $\begin{array}{l}\text { Case-control } \\
\text { study }\end{array}$ & 226 \\
\hline 7. & Van der Meer ${ }^{18}$ & $\begin{array}{c}\text { The association between } \\
\text { headaches and } \\
\text { temporomandibular disorders } \\
\text { is confounded by bruxism and } \\
\text { somatic symptoms }\end{array}$ & 2017 & ICHD-III & $\mathrm{RDC} / \mathrm{TMD}$ & Netherland & $\begin{array}{l}\text { Retrospective } \\
\text { study }\end{array}$ & 203 \\
\hline 8. & Nazeri ${ }^{19}$ & $\begin{array}{l}\text { Role of anxiety and depression } \\
\text { in association with migraine } \\
\text { and myofascial pain } \\
\text { temporomandibular disorder }\end{array}$ & 2018 & ICHD-II & RDC / TMD & Iran & $\begin{array}{l}\text { Retrospective } \\
\text { case-control } \\
\text { study }\end{array}$ & 128 \\
\hline 9. & Contreras ${ }^{20}$ & $\begin{array}{l}\text { Systemic diseases and other } \\
\text { painful conditions in patients } \\
\text { with temporomandibular } \\
\text { disorders and migraine }\end{array}$ & 2018 & ICHD-II & RDC-TMD & Brazil & $\begin{array}{l}\text { Cross- } \\
\text { sectional } \\
\text { study }\end{array}$ & 352 \\
\hline 10. & Fernandes $^{21}$ & $\begin{array}{l}\text { Painful temporomandibular } \\
\text { disorder is associated with } \\
\text { migraine in adolescents: A case- } \\
\text { control study }\end{array}$ & 2019 & ICHD-II & $\mathrm{RDC} / \mathrm{TMD}$ & Brazil & $\begin{array}{l}\text { Case-control } \\
\text { study }\end{array}$ & 1094 \\
\hline \multicolumn{9}{|c|}{ Table 1. Included Articles by Publication Year } \\
\hline
\end{tabular}

The criteria for RDC / TMD diagnostics were used for both groups. HSQ and ICHD-II were used to determine headache, showing at least one diagnosis of headache: $56.5 \%$ of patients had headache, $52.2 \%$ had migraine and $34.8 \%$ had cluster headache (Table 1). It was shown that patients with headache had greater mastication muscle tone, stress, face pain, headache and occlusal parafunctions.

Patients with TMD reported similar symptoms, suggesting a similarity, diagnosis in patients with headaches and TMD. The authors point out that education on the harmfulness of parafunctions and their reduction can reduce the intensity of headache and is a cheap, long-lasting, and effective method of treatment.

RDC / TMD Research Diagnostic Criteria for Temporomandibular Disorders; ICHD-3: The International Classification of the Headache Disorder, third edition; HSQ: Headache Screening Questionnaire; ASC-12: Allodynia Symptom Checklist; ICHD-II: International Classification for Headache Disorders, second edition; HIS: International Headache Society. Ballegaard et al. ${ }^{13}$ published a paper in 2008, in which they determined the relationship between headaches and TMD. Researchers examined 99 patients using the RDC / TMD and ICHD-II criteria.

Fifty-six percent $(56.1 \%)$ of patients with headache had TMD. Studies have shown that patients with headaches have significant problems associated with chronic TMD pain.

Depression was also more frequent in these people. The authors suggested that patients with both migraine and tension headaches had an increased risk of TMD. The cooccurrence of both dysfunctions may be a risk factor for the development of TMD, or TMD may be a risk factor for the development of headaches. Ballegaard et al. noted the need for interdisciplinary treatment of these disorders.

Bevilaqua-Grossi et al. ${ }^{14}$ hypothesized in 2009 that TMD has an effect on serious headaches. Fifty-five patients with migraine episodes, who also exhibited TMD, were studied. The RDC / TMD criteria were used to assess them. Fifteen subjects did not have TMD disorders, and these constituted the control group. Forty of the respondents (73\%) had TMD disorders. Hyperalgesia, the risk factors for which are depression, overweight and long-term pain-occurred in $40 \%$ of people without TMD. In eighty-six percent (86.9\%) of patients with TMD, myofascial pain occurred, while in $82.3 \%$ of patients there was a mixed form of TMD (myofascial and arthralgic). In conclusion, the authors reported that TMD and hyperalgesia were associated with migraine.

The next study was carried out by Tröeltzsch et al. ${ }^{15}$ in 2011. Its purpose was to determine the relationship between occlusion disorders, parafunctions, TMD, physiological and muscular factors, and the occurrence of headache. The authors focused on the essence of the problem, as headache is a common condition that affects $88 \%$ of women and $69 \%$ of men in the entire population. One thousand thirty one (1031) patients were examined over eleven months, including 436 men, ( $42.3 \%$ of respondents) and 595 women (57.7\%). The average age of the respondents was 49.6 years. Of all patients, 257 people were under 30 years of age, 474 people were aged between $30-60$ years and 288 were over 60years. Tension headaches were found in $48 \%$ of patients and migraine in $1 \%$. In turn, eighty five (85) patients were diagnosed with both tension headaches and migraines. The study used the RDC / TMD and IHS criteria. TMD symptoms were diagnosed more often in women than in men (1.7:1). The authors suggested 
that headaches were associated with TMD and occlusal disorders, but they did not indicate that treatment of these disorders can reduce pain. The study found that a gap between central occlusion and maximum intercuspal position of over 3 $\mathrm{mm}$ correlates with the occurrence of headache. As in a study by other authors, a relationship between headache and female sex and an increased incidence of headache in middle-aged women was noted. However, the intensity and frequency of attacks decreased with age. The authors point out the necessity of conducting further research in this direction. The results indicate strong relationships between stomatognathic disorders and headache.

Melo et al. ${ }^{16}$ conducted a study in 2012, to identify the prevalence of TMD symptoms and their severity in people with headaches. Sixty adults were examined and were assigned to individual groups (such as chronic headaches, episodic headaches and a control group of patients without headaches).

The International Headache Society instrument was used to diagnose headaches. TMD assessment was performed using the temporomandibular index (TMI) and by means of RDC / TMD. After the study, it was determined that TMD was a more severe disorder in patients with headaches and more often affects women than men. The authors emphasise the importance of multidisciplinary treatment in this group of patients. It was suggested that further research should be conducted to identify the relationship between these dysfunctions.

In 2014, the study of Franco et al. ${ }^{17}$ involved 158 people with TMD, including 133 women (84.2\%) aged 18 - 76 (mean age 40.1), 25 men (15.8\%) aged 18 - 62 years (mean age 41.7), and a control group of 68 people without TMD, which consisted of 52 women (76.5 \%) aged 18 - 69 years (mean age 38.4 ) and 16 men (23.5\%) aged 18 - 62 years (average age 36.8). RDC / TMD was used to assess patients with TMD, while the second edition of the International Classification for Headache Disorders was used to assess headache. The results obtained indicated that headaches occurred in $45.6 \%$ of patients in the control group (30.9\% with migraine and 14.7 $\%$ with tension headaches). However, headaches in patients with TMD accounted for $85.5 \%$. Among people with TMD, patients with migraine constituted $55.3 \%$ and tension headaches were suffered by $30.2 \%$ of subjects. In conclusion, the authors found that TMD causes an increase in the incidence of headache, that migraine was most common among these patients and that there was a relationship between TMD and primary headache.

Van der Meer et al. ${ }^{18}$ conducted a retrospective study in 2017, to which they qualified patients who completed questionnaires on headaches, stress, depression and somatic symptoms. Patients were then examined using the RDC / TMD. The HSQ and the ICHD-3 were used to assess headache. Using the available literature, those authors identified factors that influence the relationship between headache or migraine headache and TMD including age, sex, bruxism, depression, stress and somatic symptoms. Bruxism was evaluated on the basis of a questionnaire prepared by the author, and stress was evaluated using a seven-item questionnaire. Depression and somatic symptoms were assessed with the Dutch version of the Symptom Checklist-90 (SCL-90). 203 people were included in the study, with $73.4 \%$ of women. Based on the research, the authors concluded that bruxism and somatic symptoms affect migraine and TMD. Treatment of bruxism had a positive effect, reducing both TMD and headaches.

Nazeri et al. ${ }^{19}$ in 2018 conducted a study of patients aged 15 - 45, diagnosing headache in 65 people using the ICHD-II scale. There were 52 women in this group (80\% of respondents) and 13 men ( $20 \%$ of respondents). The patients were then screened using RDC / TMD and classified into one of two groups: people with TMD and people without TMD. There were 50 patients with TMD (76.9\%) and 15 (23.1\%) without. Sixty-three people without headache were qualified to the control group according to specific inclusion criteria; 25 of these $(39.7 \%)$ were from the TMD group and $38(60.3 \%)$ were from the non-TMD group. These patients were also examined for anxiety and depression using the Persian version of the Hospital Anxiety and Depression Scale-14, which consists of fourteen questions (seven for depression and seven for anxiety). Researchers showed that patients who do not have anxiety or depression showed no relationship between headache and temporomandibular joint disorders. The authors noted the need for further research in this direction.

Contreras et al. ${ }^{20}$ evaluated the relationship between the pain form of TMD and migraine and systemic diseases such as diabetes, cardiovascular disease, neck pain, body pain, ear, nose, throat and gastritis, in people of both sexes aged $18-65$. A total of 352 patients were classified into three groups: a control group of 47 people without TMD or headache, a group of 41 patients with TMD and a group of 264 people with both TMD and migraine. TMD was diagnosed using RDC / TMD and headache with ICHD-II. Eighty three percent $(83.3 \%)$ of respondents were women aged $37.7 \pm 12.7$ years. Systemic diseases were assessed by means of an interview. The authors noted that people with both TMD and migraine were more likely to suffer from pain and systemic diseases. The disorders were more likely to affect women than men.

Fernandes et al. ${ }^{21}$ described the relationship between TMD and migraine in a group of teenagers aged 13 - 15 years. ICHDII was used to assess headache and RDC / TMD to assess TMD. These authors confirmed the role of the trigeminal nerve on the pathophysiology of both TMD and migraine. Neurons from the first branch of the trigeminal nerve affected migraine pain, while neurons from the second and third trigeminal nerves affected TMD. Researchers noted a relationship between the occurrence of TMD in children and adolescents with emotional, behavioral and physical disorders. Present study did not find a difference in the incidence of TMD and headache between girls and boys. Girls who had not undergone their menstrual period were excluded from the study, so that the group of subjects would be homogeneous in terms of hormonal maturity, assuming that there might be an effect of hormones on the painful form of TMD and headaches, especially migraine. However, the relationship between TMD and headache and the need for simultaneous treatment of comorbidities was considered to increase the effectiveness of treatment.

The current literature review confirmed the relationship between TMD and headache. The authors of the articles generally agreed that problems were more common in women, and that further research should be conducted on the correlation between these disorders. The researchers also payed attention to the co-occurrence of depression, which was likely to be associated with chronic pain in patients with TMD. The authors of the independent publications selected for 
analysis noted the effect of occlusal disorders and parafunctions on the occurrence of TMD and headache. An assessment of the impact of female hormones on TMD and headache will require further observation and a larger study population. New IHS clearly makes the relationship between TMD and headache official with its own classification (11.7 headaches attributed to temporomandibular disorder).

\section{CONCLUSIONS}

The authors examined 10 carefully selected published papers that clearly showed a relationship between TMD and headache. Both headache and TMD were found to affect a large number of people. Using standardised assessment scales of both TMD and headache, there is a chance to analyse the results of other researchers. Such studies will allow metaanalysis of the data, which could help to broaden understanding of these problems and will likely find the factors conducive to reduce the number of patients with both TMD and headache.

Financial or other competing interests: None.

Disclosure forms provided by the authors are available with the full text of this article at jemds.com.

\section{REFERENCES}

[1] Abu-Arafeh I, Razak S, Sivaraman B, et al. Prevalence of headache and migraine in children and adolescents: a systematic review of population-based studies. Dev Med Child Neurol 2010;52(12) : 1088 - 97.

[2] Gooriah R, Nimeri R, Ahmed F. Evidence-based treatments for adults with migraine. Pain Res Treat $2015 ; 2015: 629382$.

[3] Lipton RB, Hamelsky SW, Kolodner KB, et al. Migraine, quality of life and depression: a population-based casecontrol study. Neurology 2000 ; 55(5) :629 - 35.

[4] Magnusson T, Carlsson GE. Recurrent headaches in relation to temporomandibular joint pain-dysfunction. Acta Odontol Scand $1978 ; 36(6)$ ) 333 - 8 .

[5] Ciancaglini R, Radaelli G. The relationship between headache and symptoms of temporomandibular disorder in the general population. J Dent $2001 ; 29(2): 93$ - 8.

[6] Headache Classification Committee of the International Headache Society. The International classification of headache disorders: 2nd edition. Cephalalgia 2004;24(Suppl 1) : 9 - 160.

[7] Olesen J, Steiner TJ. The International Classification of headache disorders, $2^{\text {nd }}$ edition. (ICDH-II). J Neurol Neurosurg Psychiatry 2004 ; 75(6):808 -11.
[8] Dworkin SF, Leresche L. Research diagnostic criteria for temporomandibular disorders: review, criteria, examinations and specifications, critique. J Craniomandib Disord 1992;6(4) :301 -55.

[9] Helkimo M. Studies on function and dysfunction of the masticatory system. II. Index for anamnestic and clinical dysfunction and occlusal state. Sven Tandlak Tidskr 1974;67(2):101 -19.

[10] Agerberg G, Helkimo M. Symptomatology of patients referred for mandibular dysfunction: evaluation with the aid of a questionnaire. Cranio $1987 ; 5(2): 157$ - 63.

[11] Headache Classification Committee of The International Headache Society (HIS). The International classification of headache disorders: 3rd edition (Beta Version). Cephalalgia 2013;33(9):629 - 808.

[12] Glaros AG, Urban D, Locke J. Headache and temporomandibular disorders: evidence for diagnostic and behavioural overlap. Cephalalgia $2007 ; 27(6): 542$-9.

[13] Ballegaard V, Thede-Schmidt-Hansen P, Svensson P, et al. Are headache and temporomandibular disorders related? a blinded study. Cephalalgia 2008;28(8):832 - 41.

[14] Bevilaqua-Grossi D, Lipton RB, Napchan U, et al. Temporomandibular disorders and cutaneous allodynia are associated in individuals with migraine. Cephalalgia 2010;30(4):425-32.

[15] Troeltzsch M, Cronin RJ, Brodine AH, et al. Prevalence and association of headaches, temporomandibular joint disorders and occlusal interferences. J Prosthet Dent 2011;105(6):410 - 7 .

[16] Melo CEB, Oliveira JLG, Jesus ACF, et al. Temporomandibular disorders dysfunction in headache patients. Med Oral Patol Oral Cir Bucal 2012;17(6):e10426.

[17] Franco AL, Gonçalves DAG, Castanharo SM, et al. Migraine is the most prevalent primary headache in individuals with temporomandibular disorders. J Orofac Pain 2010;24(3):287 - 92.

[18] Van Der Meer HA, Speksnijder CM, Engelbert RHH, et al. The association between headaches and temporomandibular disorders is confounded by bruxism and somatic symptoms. Clin J Pain 2017;33(9):835 - 43.

[19] Nazeri M, Ghahrechahi HR, Pourzare A, et al. Role of anxiety and depression in association with migraine and myofascial pain temporomandibular disorder. Indian J Dent Res 2018;29(5) :583 - 7 .

[20] Contreras EFR, Fernandes G, Ongaro PCJ, et al. Systemic diseases and other painful conditions in patients with temporomandibular disorders and migraine. Braz Oral Res 2018;32 : e77.

[21] Fernandes G, Arruda MA, Bigal ME, et al. Painful temporomandibular disorder is associated with migraine in adolescents: a case-control study. J Pain 2019;20(10):1155 - 63. 